\title{
"The pen is a powerful weapon; it can make you change": The value of using reflective writing with adolescents
}

\author{
Lisa Wegner, BSc OT (Wits), MSc OT (UCT), PhD (UCT) \\ Associate Professor, Department of Occupational Therapy, University of the Western Cape
}

Patricia Struthers, BSc PT (UCT), MPhil (UWC), PhD (UWC)

Associate Professor, School of Public Health, University of the Western Cape

\section{Suraya Mohamed, Nat Dip (RAD) (Cape Technikon), MPH (UWC), PhD (UWC)}

Lecturer, School of Public Health, University of the Western Cape

Introduction: Adolescent programmes have been criticised for implementing activities but not allowing opportunities for reflection. One way that reflection can be facilitated is through writing. This paper describes the use of reflective writing with adolescents as part of a health promoting schools project in Cape Town, South Africa.

Method: The project included an annual leadership camp for adolescent learners. A descriptive, qualitative study was conducted to describe how the learners responded to writing as a means to express their feelings about, and experiences of, the camp. Thirty learners participated in two writing sessions resulting in 53 written reflections that were analysed thematically.

Findings: Three themes emerged: (I) Reflections on self; (2) Reflections on self in relation to others; and (3) Reflections on writing. Participants reflected on connecting with complex, positive and negative feelings, and felt that reflective writing had enabled them to express themselves with courage and honesty, connect with themselves, identify weaknesses and let go of negative emotions and feelings. Furthermore, writing was perceived as being non-judgmental, providing a sense of relief and release, and evoking emotions.

Conclusion: Reflective writing enabled the participants to acknowledge personal changes and development, and provided insight into their feelings and experiences. This study shows the value of reflective writing for use by health professionals such as occupational therapists, as a tool for empowerment in the pursuit of health and wellbeing.

Key words: reflective writing, adolescents, empowerment, health promoting schools

\section{INTRODUCTION}

Adolescent programmes have been criticised for concentrating on implementing activities but not allowing sufficient opportunities for reflection'. In order for adolescents to be able to reflect in a critical way, they need to become aware of, and understand, "... structures, processes, social values and practices they seek to alter"2:47. Skilled, knowledgeable adults can guide adolescents through the process of reflection', which can be facilitated through methods such as reflective writing ${ }^{3}$. Reflective writing is the expression of the mental process of reflection on paper ${ }^{4}$ and is central to the notion of learning from experience ${ }^{5}$. By reflecting on self and actions, meaningful change may be facilitated'. Reflective writing is frequently used in academic settings as part of experiential learning to facilitate clinical and other forms of reasoning in tertiary level students ${ }^{6}$ and by health professionals to reflect on their practice ${ }^{7}$. Mental health professionals including occupational therapists use writing such as journaling and poetry as a therapeutic tool to, for example, deepen clients' insight, and promote emotional expression and personal exploration ${ }^{6}$.

This paper describes the use of reflective writing with adolescents as part of a health promoting schools project in Cape Town, South Africa. A health promoting school is a school that is constantly increasing its capacity as a healthy setting for living, learning and working ${ }^{8}$. The health promoting schools approach encourages members of the school community - including learners - to be actively involved in addressing health related issues and promoting health ${ }^{8}$. The aim of the project was to support schools to become health promoting schools. The focus was on building and strengthening the human and organisational capacity of the schools as caring and empowering environments with emphasis on addressing tuberculosis (TB) and HIV . The five-year project was implemented between 2008 and 2013 and was a universityschool partnership between the University of the Western Cape and three high schools in Cape Town. The schools were situated in a community characterised by social problems including relatively high rates of unemployment ${ }^{9}$, gangsterism (and its associated violence ${ }^{10}$ ), substance use with resultant sexual risk behaviour ${ }^{11}$ and teenage pregnancy ${ }^{12}$. At the time of the project one of the major health problems in this community was TB, with 10 per 1000 of the population infected ${ }^{13,14}$.

The project used multiple strategies with various activities to engage the school community (including learners, educators, other staff, and community organisations working with schools and young people $\left.{ }^{15}\right)$. One of these strategies was an annual camp for learners which brought together learners from the three schools ${ }^{16}$. The goals of the camp were to develop the learners' leadership skills including interpersonal communication, public speaking, teamwork and assertiveness; foster a deeper understanding of gender and power relations; and increase knowledge of health, TB and HIV. Camp activities and methods used were designed to build capacity and empower learners; therefore, experiential learning with an interactive, democratic, participatory approach whilst having fun was the underlying approach ${ }^{16}$. This approach was based on

${ }^{a} \mathrm{HIV}$ was included as it has been estimated that in South Africa over $50 \%$ of people with tuberculosis are also HIV positive ${ }^{14}$. 
Jensen's description of the development of action competence meaning that learners are enabled to make their own decisions about health, and identify the personal and social changes and actions required to move towards their vision of health ${ }^{17: 422}$. Action competence includes developing vision, commitment, knowledge, insight and action experience (concrete action during learning), as well as generic learning skills ${ }^{17}$. The five female and three male camp facilitators ${ }^{\mathrm{b}}$ created a welcoming social climate. Cargo et al. described a theoretical framework of youth empowerment that emphasised a "transactional partnering process between adults and youth" 18:569. When adults created a "welcoming social climate", it "enabled and engaged youth to take responsibility, voice opinions, make decisions and take action"18:569.

As part of the camp activities, the learners were involved in two writing sessions to give them an opportunity for reflection. The facilitators questioned how the learners would respond to writing as a means to express their feelings of, and experiences about, the camp. Therefore, the research questions for the study were: (I) What were the learners' feelings about, and experiences of, being at the camp? (2) What were the learners' experiences of reflective writing?

\section{METHODS}

\section{Research design}

A qualitative, descriptive research design was selected for this study. In addition to summarising particular events, a descriptive research design enables researchers to explore the "meanings participants attribute to those events"19:336.

\section{Participant selection}

Thirty learners (I 5 males and I 5 females) aged between 14 and 18 years from the three high schools (five males and five females from each school) attended the four-day leadership camp. The learners attending the camp were selected by their respective educators largely as a result of their involvement in the health promoting schools project and their leadership potential. All learners who attended the camp participated in the reflective writing sessions.

\section{Data collection}

Data were collected at the camp during two sessions of reflective writing. During the first session held on the evening of day three, the facilitator (one of the authors) asked the participants to reflect on, and write about: "Your feelings and experiences of being at the camp". It was evident to the facilitators that the participants became totally absorbed in the writing. Originally five minutes were allocated for the activity but participants wrote for fifteen to twenty minutes. For this reason, in the second session on day four, the facilitator asked participants to: "Write about how it was to express your feelings in writing".

At the start of each session, participants were asked to "find a safe, private place in the room". In order for the learners to become calm after a busy day, the session began with a relaxation activity using deep breathing techniques with soft music playing in the background. The facilitator requested the participants to respond to the questions and write about whatever came to mind. The participants' home languages and languages of instruction at their schools were Afrikaans and/or English; therefore, participants were invited to write in their preferred language. At the end of each session, participants were invited to hand in their reflections. Twenty four out of the 30 participants, submitted reflections after the first session and 29 submitted reflections after the second session.

\section{Analysis}

The 53 hand-written reflections were typed and then analysed in the original language in which they were written, as the researchers were fluent in both languages. For purposes of this paper the

${ }^{b}$ The three authors were facilitators.
Afrikaans quotes were translated into English with only minor edits, where necessary, to facilitate reading. Braun and Clark describe thematic analysis as "a method for identifying, analysing and reporting patterns (themes) within data ${ }^{20: 79}$. Using this method of thematic analysis, the researchers each read through the transcripts a few times and then identified codes. This was followed by a discussion on their codes to obtain consensus, after which themes based on identified patterns in the reflections were defined and developed.

\section{Trustworthiness}

Several methods of ensuring trustworthiness were employed in the current study. Credibility can be achieved through prolonged engagement or immersion in the study context ${ }^{21}$, and took place when the researchers as the camp facilitators spent an extended period of time with the participants during the four day camp. This meant that the researchers had time to check their perspectives of the participants, and the participants were able to become familiar with the researchers. Triangulation means obtaining "convergence of multiple perspectives for mutual confirmation of data"21:219. In the current study, triangulation of data sources was obtained by involving multiple (30) participants from three schools, and obtaining multiple written reflections during two sessions. Furthermore, triangulation of investigators was ensured through the use of three researchers who engaged in a process of reflexivity by interrogating their assumptions, ideas and perspectives with one another whilst conducting the camp, analysing the data, and writing up the findings. Peer examination took place as the researchers discussed the research process and findings with the other members of the health promoting schools project who were not involved directly in the current research study and who had qualitative research experience.

\section{Ethics}

The study received ethics approval from the Research Ethics Committee of the University of the Western Cape and the Western Cape Education Department (200804 I I-0025). Written informed consent was obtained from parents or guardians of the participants and the participants gave written assent. Participants submitted their reflective writing voluntarily. They were informed that they could highlight any parts that they did not wish to be made public; however, none of the participants did this. The reflections were submitted anonymously, but participants were required to indicate their gender and age.

\section{FINDINGS}

Three themes emerged from the analysis of the reflections: (I) Reflections on self; (2) Reflections on self in relation to others; and (3) Reflections on writing.

\section{Theme One: Reflections on self}

This theme deals with the participants' self reflections. They were able to write about, and get in touch with, their emotions and feelings:

I'm thinking about my life, my dreams, my choices. (Male, I 5 years)

The participants wrote about how the camp had developed self-awareness and built their self-esteem:

This camp has done some major things in my life, really. Knowledge I want to take further. Today I'm feeling so good about myself, because I could open up and see what's inside of me, who the real [participant's name] really is and what he really likes. (Male, 16 years)

Some participants described feeling good about themselves, regardless of how they thought other participants viewed them:

... it's not who they think or say you are. THIS IS ME AND I LOVE MYSELF. So why don't you LOVE ME 4 ME!!! That is how I feel and this is what I'm like AND THERE AIN'T NO WAY you can TAKE IT AWAY. THIS IS REAL!! DON'T CHANGE IT and if you do, don't worry l'Il love you more than before. (Male, 15 years) 
The following participant reflected on becoming a man and the meaning of masculinity and gender norms, thus showing evidence of developing gender identity:

There is loads of stuff that I still need to find out and learn. Confidence and manlyhood stood out for me, because you are judged by how manly you are. (Male, I5 years)

Participants were able to identify negative emotions and feelings that they were experiencing. At times their relationships with their friends made them feel unhappy, hurt, angry or betrayed. One participant, unhappy and missing the security of home indicated that he felt afraid and unsure of himself, but at the same time realised that he needed to take responsibility to change:

I am angry. I am afraid and unsure of myself. I feel I have no worth. I have given up hope. I miss my home, my comfort zone. It is the only place I feel safe. The place where no one can hurt me. I am king there. I don't like it when people laugh at me. I wish I was someone else. I am hurt but I cannot cry. Help. Help yourself. (Male, I 5 years)

The range of emotions that the participants experienced, sometimes simultaneously, confused them. As they acknowledged that they had complex feelings, they discovered the different sides of themselves. At times the feelings were described metaphorically:

My emotions are like a rainstorm. It makes people unhappy. It makes people sad. It's dark and builds up into a dark cloud. But when the rain is gone sometimes a rainbow starts to appear and clear skies with a bright smiling sun for all to see. Even the weather man is glad to broadcast it. Emotions I don't know why we have it but without it I wonder how we would have been. (Female, 17 years)

The participants identified new learning that had taken place in areas such as gender sensitivity, standing up for what they believed in, talking publicly, not being shy, gaining knowledge on HIV and $\mathrm{TB}$, leadership skills, and listening to other people:

The HPS [health promoting schools] group has answered questions I didn't even know I wanted to ask because of the knowledge they have given me. From tomorrow afternoon [returning home] I will start practising what they taught me in real life - to see if I can be assertive, confident, trust myself and others. (Female, 16 years)

Participants expressed how the camp motivated them to pursue their goals as part of their vision for the future:

I just told myself that I will reach out for my dreams and that I will make them come true and it will be a lot of hard work. At first I will need to complete school and then I can become what I want. (Female, 14 years)

\section{Theme Two: Reflections on self in relation to others}

This theme deals with the participants' reflections on social connections and interactions with other people. A predominant feature in their reflections was the recognition of the contribution that peers at the camp had made towards their development:

These bright and in-control young people taught me to believe and trust in myself. (Male, I 5 years)

The participants expressed positive feelings towards one another. This was important as it included not only friends from their school but learners from the other schools too. This indicated the value of bringing the learners from the three schools together:

It was a wonderful experience to get to know other adolescents from other schools. We can respect one another and be friendly. Everybody supported one another like a team. Nobody was judged for his opinion or answer. Even though everybody came from different backgrounds, it did not matter. (Female, 15 years)

The participants reflected on the positive, new friendships they had formed with learners from the other schools:
My new fantastic friends. I felt full and complete. I was searching for something I longed for - friends. (Male, 16 years)

The facilitators were present at the camp both day and night, with some discussions between the participants and the facilitators continuing into the early hours of the morning. The participants valued the relationship of trust with the facilitators whom they regarded as positive adult role models:

You [facilitators] rock. You guys made me feel smart and normal in this cruel, cruel world. It was nice to be with people I could relate to and trust with my feelings and problems. (Male, 16 years)

The participants acknowledged the valuable contribution that the facilitators had made to their development:

You all helped me to find the true me. You showed me that it only takes believing, assertiveness and self-confidence to reach your goals and no matter who or what may stand in our way there's always hope. You showed me how to fight for what I want and what I believe in. You taught me that there's always a choice no matter what the predicament or situation. (Female, 17 years)

As a result the participants expressed gratitude towards the facilitators:

Do people like you get appreciated by your children, husbands, wives, family, friends? I hope that they appreciate you because what you have done in our lives is unforgettable. Thank you for your gift to us, I appreciate it a lot. (Male, 16 years)

The participants wrote about their own learning and consequent changes experienced on the camp which they were keen to share with other people:

I am going to start with myself first then I will take further steps to inform my community or school about what I have learnt. The camp has really made me another person, it feels to me to learn more was something good. And I like to learn new things. (Female, I 7 years)

The changes that they had experienced in themselves enabled them to identify the potential in their peers:

I would just like to say you [peers] will all be great leaders and will definitely reach your goals and dreams. I believe in you guys! (Male, age unknown)

The participants reflected on the skills they had learnt in order to relate to others individually and in groups. This included an awareness of gender constructs and improved skills for communication, teamwork and leadership. For example, they identified communication skills as important for their leadership development:

We had not been yelling to [at] each other and it's very good to communicate like that. I mean we were communicating nicely with each other without being mad. We all did work with happiness and pride and I did like it. (Male, 16 years)

Many participants wrote about their connection with God, acknowledging and thanking God for making the camp possible and providing them with new opportunities:

I'm really glad that God made it possible for me to meet someone like that in this kind of way. I know God has a plan for my life but need to get rid of the hurt inside of me. THANK YOU FOR ALL THIS and I KNOW GOD WILL BLESS YOU. I'm going to miss the HPS-Team. (Female, 17 years)

\section{Theme Three: Reflections on writing}

In this theme the participants' responses to the reflective writing process are described as well as their feelings that emerged as a result of the writing. Reflective writing was a new experience for the participants; however, once they started with the actual process of writing, they were surprised at how easy and comfortable it was to write. They realised the potential reflective writing had for them to be able to express themselves:

It felt like I came to know myselffor the first time. The pen is a power- 
ful weapon, it can make you change. Just like my whole perspective of myself changed when the ink got onto the paper. It felt like I was betraying myself but as I carried on, it got better and better and the words just flowed out of my mind and most importantly my heart. Getting my feelings and emotions on paper helped me to realise what potential I have and how to deal with my different emotions. (Male, 17 years)

Although some of them acknowledged that they did not normally enjoy writing, the writing process unleashed an outpouring of words. Many of the participants referred to this process of writing as making them feel free and relieved:

Wow! Last night's writing made me more confident to start writing more. I never knew that I could focus so hard and yet feel so free. I felt a sense of relief to just write what was on my mind and words just flew through my head and I don't even know where they came from. When time was over I knew I had to stop but my mind didn't allow me to, and that came as a shock to me because most of the time I don't like any form of writing. (Male, age unknown)

The non-verbal, non-judgemental medium of writing enabled the participants to articulate their emotions and feelings freely:

Sometimes there's no one to understand you as a teenager. I think if you write it on a page it cannot judge you. It doesn't talk back at you or ask you questions about this, that and the other. (Female, 17 years)

The process of engaging in reflective writing enabled the participants to access, connect with, and express, their feelings with honesty. They viewed writing as a strategy for dealing with difficult issues:

It felt wonderful to get it out. It [writing] made me focus on the good and also gave me strategies on different ways to handle the negative things in life. It's an awesome way of getting to know yourself. It's a way of being honest with oneself. You can't lie to yourself, especially not on paper. It taught me to trust myself and to deal with my feelings. (Female, 17 years)

The participants also expressed how writing and reflecting required courage:

I am writing with courage about myself and how I am. My biggest fear was: 'Will I ever find things inside me? Will I be able to bring out those feelings or not?' (Male, 16 years)

The honesty that writing evoked in the participants enabled them to identify their weaknesses which they sometimes experienced as being disconcerting:

I learned something about myself. I discovered my weaknesses and the true reason I can't walk alone or stand up for myself. It was a little disheartening to see everything that I wrote, but it made me realise that I still need to reconnect with myself. (Male, I 5 years)

The participants reflected on how the writing had enabled them to let go of past negative feelings and how it made them feel more confident about themselves:

You relive everything and then let go of everything you feel about yourself and others. To be able to write about how you feel also builds confidence. (Male, 17 years)

Writing was an emotional experience for some participants as they reflected on themselves:

I am writing with tears that want to come out of my eyes, really for the first time I learnt a lot about myself, my weaknesses. (Male, 16 years)

The cyclical process of reflecting, writing and further reflecting on the writing allowed the participants to contemplate, and release their negative feelings, thus enabling them to access positivity:

The empty page at first symbolised my soul and as I wrote I filled the page with all the negative words and emotions whilst clearing my heart of all the negatives, giving space for the positive to come in. (Male, 15 years)

\section{DISCUSSION}

Considering the findings of the study, it was clear that, as the participants reflected on their experiences through writing, they were able to acknowledge the personal changes and development that had occurred during the camp. The first two themes dealt with the participants' reflections about themselves and their relationships with other people. This may be regarded as reflections on an intrapersonal, and an interpersonal, level. The two themes provided an understanding of the participants' feelings about, and experiences of, being at the camp and the personal development that had happened as result. Cargo et al. ${ }^{18}$ referred to fostering positive development as actualising youth potential which is part of the process of becoming empowered, and ultimately leads to constructive change. Clearly, the findings of the current study showed that the learners' potential had been actualised and thus empowerment had taken place, as was evident from their reflective writing. Empowerment is a key principle of health promotion ${ }^{8}$ and is described as a process that promotes autonomy, freedom, knowledge, self-esteem, self-confidence and control over health and life ${ }^{22}$. Empowering adolescent learners to address health and wellbeing issues is also an important aspect of developing a health promoting school which encourages learners to develop action competence in order to be able to facilitate change ${ }^{23}$.

The findings indicated that at the intrapersonal level, the participants felt that during the camp they had connected with personal, complex, positive and negative feelings in an honest or authentic way. They reflected on developing self-awareness and identifying new learning that had occurred as well as future goals. This raised their self-awareness and developed self-esteem and self-confidence. At an interpersonal level in terms of social connections and interactions, the participants reported on the development of social skills and leadership skills, feeling positive towards their peers at the camp and developing new friendships.

Previous research has indicated several factors that facilitated empowerment of adolescents. Chinman and Linney ${ }^{24: 395}$ identified "active participation, awareness of the surrounding world, and identification of strengths" as key components of the empowerment process for adolescents. This may be regarded as psychological empowerment which has been defined as a process of change involving intrapersonal, interactional and behavioural components ${ }^{25}$ that results in a "feeling of greater control over one's life following active group membership" 26:41. It is evident from the findings of the study, that the participants had experienced some degree of psychological empowerment during the camp due to the changes and development that they had identified in the areas of intra- and interpersonal functioning through their reflective writing.

Furthermore, the participants identified the camp facilitators as positive role models and expressed gratitude towards them. The major role of health promoters is facilitation rather than direction, and includes setting up structures and systems that promote community initiatives and the adoption of a mentoring and mediating role $^{26}$. The findings of the study support the transactional partnering process of empowerment between adults and youth ${ }^{18}$. It is evident in the participants' reflections that they appreciated the opportunities that were provided through the facilitators' care, respect, encouragement and belief in them. In addition, the facilitators created a welcoming social climate by means of the safe, supportive physical and emotional environment at the camp, which has been identified as crucial to creating an empowering environment ${ }^{18}$.

The third theme dealt with the participants' reflections about their experiences of reflective writing. They felt that reflective writing had enabled them to express themselves with courage and honesty, connect with themselves, identify weaknesses and let go of negative emotions and feelings. They perceived reflective writing as being non-judgmental, providing a sense of relief and release, and evoking emotions. The safe and supportive environment that was created through reflective writing facilitated personal and social development which was empowering for the participants. Clearly, 
the reflective writing created a facilitative environment or space in which the participants were able to look deeply within themselves without having to engage with anyone else such as during focus group discussions or even individual interviews. Adolescents often do not express themselves openly to others about their feelings without some encouragement. It is possible that adolescents might not get many opportunities to be self- reflective in school. If they can develop the skill to be self- reflective through writing, this could be an activity that they could do by themselves, especially if they see the value of it for their own personal development. As the opinions of peers are important to adolescents, they might be reluctant to share their feelings with their peers verbally in groups. By doing introspection through reflective writing, adolescents might be able to better make sense of their thoughts and feelings through the process of writing rather than talking.

\section{Limitations}

The main limitation of the study was that it took place in a particular community in Cape Town; therefore, the findings should be viewed within this context and may not be applicable in different settings. This could however, be viewed as a strength in the search for understanding issues and pertinent aspects of occupational therapy practice within contexts such as the one in which the schools were situated.

\section{Implications for practice}

The World Health Organisation's Global Health-for-All policy for the $2 I^{\text {st }}$ century ${ }^{27}$ requires all health professions to re-define their roles in order to meet the diverse needs of the populations with whom they work. The current study provides an example of how occupational therapists might re-define their role by working in schoolsettings to promote health and wellbeing amongst adolescents. It is important that occupational therapists provide adolescents with opportunities not only to engage in relevant activities, but also to reflect on their learning, skills, feelings and experiences. Reflective writing can be incorporated into activities to enable adolescents to learn from their experiences; this in turn brings about meaningful change. The positive development that occurs as a result facilitates empowerment and develops action competence which enables adolescent learners to make changes as part of their role in health promoting schools.

\section{CONCLUSION}

In conclusion, the study highlights the value of using writing to facilitate reflection in adolescents as it enabled them to acknowledge personal changes and development, and provided insight into their feelings and experiences. This in turn shows the value of reflective writing for use by health professionals such as occupational therapists as a tool for empowerment in the pursuit of health and wellbeing.

\section{FUNDING}

This work was supported by the United States of America's President's Emergency Plan for AIDS Relief (PEPFAR) through the Centres for Disease Control and Prevention (CDC) [Grant Number 5U2GPSO0 I083]. The contents of this article are solely the responsibility of the authors and do not necessarily represent the official views of PEPFAR or the CDC.

\section{ACKNOWLEDGMENTS}

The authors are grateful to the schools, principals, learners and educators for their participation in the study, and to the Western Cape Education Department for their support. We also thank our colleagues Karen Collett, Estelle Lawrence, Nadeen Moolla and Brenda Sonn for their involvement in the Health Promoting Schools Project.

\section{REFERENCES}

I. Punch S. Research with children. Childhood. 2002; 9(3): 32I-34I. Doi: I0.II 177/0907568202009003005.
2. Jennings LB, Parra-Medina DM, Hilfinger M, DeAnne K, McLoughlin $K$. Towards a critical social theory of youth empowerment. Journal of Community Practice. 2006; I 4(I-2): 3I-55.

3. Fortin R, Jackson SF, Maher J, Moravac C. I WAS HERE: Young mothers who have experienced homelessness use photovoice and participatory qualitative analysis to demonstrate strengths and assets. Global Health Promotion. 20I5; 22(I): 8-20.

4. Chandler GE. A creative writing program to enhance self-esteem and self-efficacy in adolescents. Journal of Child and Adolescent Psychiatric Nursing. 1999; 12: 70-78. doi: 10.1 I I I/j. I744-6I7I. 1999. tb00047.

5. Jasper MA. Using reflective writing within research. Journal of Research in Nursing, 2005; 10(3): 247-260. doi: 10.1177/174498710501000303.

6. Haertl K. Journaling as an assessment tool in mental health. In: Hemphill-Pearson BJ, editor. Assessments in occupational therapy mental health: An integrative approach (second edition). USA: SLACK Incorporated; 2008: 61-79.

7. Bolton G. Reflective practice: Writing and professional development (third edition). London, UK: SAGE Publications; 2010.

8. World Health Organization. Health-Promoting Schools: A healthy setting for living, learning and working. World Health Organization; 1998. <http://www.who.int/school_youth_health/media/en/92. pdf> (7 June 2016).

9. Statistics South Africa. Census 20I I. Pretoria, South Africa: Statistics South Africa; 2012. < https://www.statssa.gov.za/publications/ P030I4/P030I420II.pdf> (5 May 2017).

10. Jensen S. Gangs, politics and dignity in Cape Town. Johannesburg, South Africa: Wits University Press; 2008.

I I. Harker N, Kader R, Myers B, Fakier N, Parry C, Flisher, A, Peltzer $\mathrm{K}$, Ramlagan S, Davids A. Substance abuse trends in the Western Cape: A review of studies conducted since 2000. Human Sciences Research Council, 2008. <www.hsrc.ac.za/en/research-outputs/ ktree-doc/25II > (5 May 20I7).

12. Reddy SP, James S, Sewpaul R, Koopman F, Funani NI, Sifunda S, et al. Umthente Uhlaba Usamila - The South African Youth Risk Behaviour Survey 2008. Cape Town: South African Medical Research Council; 2010.

13. Den Boon S, van Lill SWP, Borgdorff MW, Enarson DA, Verver S, Bateman ED, et al. High prevalence of tuberculosis in previously treated patients, Cape Town, South Africa. Emerging Infectious Diseases. 2007; I3(8): II89-1।94.

14. World Health Organization. "South Africa: Tuberculosis profile." 2009. <https://extranet.who.int/sree/Reports?op=Replet\&name=/ WHO_HQ_Reports/G2/PROD/EXT/TBCountryProfile\&ISO2=ZA \&outtype $=\bar{h} t \mathrm{tml}>(\mathrm{I} 2$ May 20I I)

15. Struthers P, Rooth E, Collett K, Lawrence E, Mohamed S, Moola N, Sonn B, Wegner L. Health Promoting Schools: An action guide in the context of TB and HIV and Aids. Bellville, South Africa: University of the Western Cape; 2013.

16. De Jongh J, Wegner L, Struthers P. Developing capacity amongst adolescents attending a leadership camp. South African Journal of Occupational Therapy. 20I4; 44(3): 6-10.

17. Jensen BB. A case of two paradigms within health education. Health Education Research. 1997; 12(4): 419-428.

18. Cargo M, Grams GD, Ottoson JM, Ward P, Green LW. Empowerment as fostering positive youth development and citizenship. American Journal of Health Behavior. 2003; 27 (Supplement I): S66-S79.

19. Sandelowski M. Focus on research methods: Whatever happened to qualitative description? Research in Nursing \& Health. 2000; 23: 334-340.

20. Braun V, Clarke V. Using thematic analysis in psychology. Qualitative Research in Psychology. 2006; 3: 77-I0I.

21. Krefting L. Rigor in qualitative research: The assessment of trustworthiness. The American Journal of Occupational Therapy. 1991; 45(3): $214-222$.

22. Tengland PA. Empowerment: A goal or a means for health promotion? Medicine, Health Care and Philosophy. 2007; 10(2): 197-207.

23. St Leger L. Protocols and guidelines for health promoting schools. Promotion \& Education. 2005; 12(3-4): 145-147.

24. Chinman MJ, Linney JA. Towards a model of adolescent empowerment: Theoretical and empirical evidence. The Journal of Primary 
Prevention. 1998; 18: 393-413.

25. Zimmerman M. Psychological empowerment: Issues and illustrations. American Journal of Community Psychology. 1995; 23: 58I-599.

26. Rissel C. Empowerment: The holy grail of health promotion? Health Promotion International. 1994; 9(I): 39-47.

27. World Health Organization. "Final report: Fiftieth session of the WHO Regional Committee for Africa." WHO Regional Office for Africa. 2000. <file:///C:/Users/admin/Downloads/AFRRC50-17\%20Final\%20Report\%20(I).pdf> (4 June 20I6).

\section{Corresponding Author}

\section{Lisa Wegner}

Iwegner@uwc.ac.za 